\title{
The Course of Post-Traumatic Amnesia: Three Little Words
}

\author{
M.L. Schwartz, F. Carruth, M.A. Binns, C. Brandys, R. Moulton, \\ W.G. Snow and D.T. Stuss
}

\begin{abstract}
Objective: To provide a simple means of "real time" recognition of emergence from post-traumatic amnesia (PTA). Methods: Ninety-one patients with traumatic brain injury (PBI); 53 minor (GCS 13-15), 19 moderate (GCS 9-12), 18 severe (GCS 3-8). Twenty-seven control subjects treated at two regional trauma units for their acute phase and followed in a hospital-based research institute were studied prospectively. Subjects were examined repeatedly following injury with the Galveston Orientation and Amnesia Test (GOAT) and tests of their ability to learn and retain new information. Word triplets balanced for concreteness and frequency were presented. Immediate and 24-hour recall were tested. If 24-hour recall was imperfect, recognition was tested by presenting the 3 target words and 6 distracters. The target words were then re-presented and recall was tested the next day. The time intervals to first perfect recognition and first free perfect recall were compared with the patients' first GOAT score of 75 or greater on 2 successive days. Simple line drawings of common objects were also presented to the subjects using an identical paradigm. The outcome measures were GOAT, 3-word recognition and recall, 3 picture recognition and recall. Results: For all categories of head injury severity, the median interval to perfect free recall of words followed the achievement GOAT criterion by a significant interval. The mean GOAT scores for perfect 3-word recall and recognition corresponding to minor, moderate and severe injuries were 97,90 and 88 , and 97,76 and 68 respectively. The recognition and recall of pictures preceded the recognition and recall of words by approximately 1 day. Conclusions: The orientation measures of the GOAT that contain material that the patient knew prior to injury obscure the determination of recovery of continuous memory and should be tested separately. Three-word recall which is simpler to administer than the GOAT is a more reliable measure of emergence from PTA. For patients who are dysphasic or who do not share a common language with the examiner, 3-picture recognition and recall may substitute for word recognition and recall.
\end{abstract}

RÉSUMÉ: L'évolution de l'amnésie post-traumatique: trois petits mots. Objectif: Le but de notre étude est de fournir un moyen simple de reconnaissance "en temps réel" de l'émergence de l'amnésie post-traumatique (APT). Méthodes: Nous avons étudié quatre-vingt-onze patients ayant subi un traumatisme crânien. Le traumatisme était mineur chez 53 (GCS 13-15), modéré chez 19 (GCS 9-12) et sévère chez 18 (GCS 3-8). Vingt-sept sujets contrôles traités en phase aiguë dans deux unités régionales de traumatologie et suivis dans un institut de recherche hospitalier ont été étudiés prospectivement. Suite à leur traumatisme, les sujets ont été examinés à plusieurs reprises au moyen du test d'orientation et d'amnésie de Galveston (TOAG) et de tests pour évaluer leur capacité d'apprentissage et de rétention de l'information. Des mots en triplets, balancés quant à leur signification concrète et à leur fréquence, leur étaient présentés. Nous avons évalué la mémoire d'évocation immédiate et de 24 heures. Si la mémoire d'évocation de 24 heures était imparfaite, la reconnaissance était évaluée en présentant 3 mots cibles et 6 mots pour distraire leur attention. Les mots cibles étaient ensuite représentés et la mémoire d'évocation était évaluée le lendemain. Les intervalles jusqu'à la première reconnaissance parfaite et la première évocation parfaite libre étaient comparés au premier score TOAG de 75 ou plus sur 2 jours successifs. Des dessins aux lignes simples d'objets familiers étaient également présentés aux sujets au moyen d'un paradigme identique. Les réponses étaient mesurées au moyen du TOAG, de la reconnaissance des triplets et de leur évocation, de la reconnaissance de trois images et de leur évocation. Résultats: Pour toutes les catégories de sévérité de traumatismes crâniens, l'intervalle médian jusqu'à la reconnaissance libre parfaite de mots suivait le score TOAG et l'écart était significatif. Les scores TOAG pour une évocation parfaite de 3 mots et la reconnaissance correspondant à des lésions mineures, modérées et sévères étaient de 97,90 et 88 , et 97, 76 et 68 respectivement. La reconnaissance et l'évocation d'images précédaient d'à peu près une journée la reconnaissance et l'évocation de mots. Conclusions: Les mesures d'orientation du TOAG qui contiennent du matériel connu du patient avant le traumatisme masquent l'évaluation de la récupération de la mémoire continue et devraient être évaluées séparément. L'évocation de 3 mots, qui est plus simple à administrer que le TOAG, est une mesure plus fiable pour indiquer que le patient sort de l'APT. Pour les patients qui sont dysphasiques ou dont la langue n'est pas celle de l'examinateur, la reconnaissance et l'évocation de trois images peuvent être substituées à la reconnaissance et à l'évocation de mots.

Can. J. Neurol. Sci. 1998; 25: 108-116

Most clinicians who care for patients with head injuries have a personal understanding of post-traumatic amnesia (PTA) and consider that the length of PTA depends on, or may be taken as an indication of the severity of brain injury. In clinical practice, it is usually determined in retrospect when the patient is seen in follow-up. This post hoc determination of PTA is very often unreliable because the days in hospital tend to be undistinguished and there are few signal events that serve to date the moment of emergence from the period of time in which the patient does not have "continuous awareness". ' Symonds and Russell stated that "post-traumatic amnesia is taken to be the end of time from which the patient can give a clear and consecutive account of what was happening around him". ${ }^{2}$ As patient management decisions, for example, readiness for rehabilitation

From the Sunnybrook Health Science Centre (M.L.S., F.C., W.G.S.); Rotman Research Institute of Baycrest Centre for Geriatric Care (M.A.B., D.T.S.); St. Michael's Hospital (C.B., R.M.); Department of Surgery (Neurosurgery), University of Toronto (M.L.S.. R.M.); Department of Psychology and Medicine (Neurology), University of Toronto (D.T.S.), Toronto.

RECEIVED JULY 11, 1997. ACCEPTED SEPTEMBER 22, 1997.

Reprint requests to: Michael Schwartz, 2075 Bayview Avenue, Suite A129, Toronto, Ontario, Canada M4N 3M5 
or discharge from the acute care setting, are in part based on the "return of continuous memory", ${ }^{3}$ it is important to have a method of assessing PTA that has relevance to the clinician, that truly reflects the patient's ability to use memory functionally and yet is easy to administer at the bedside.

Various researchers have developed methods that amount to operational definitions of post-traumatic amnesia. Brooks described a method of determining whether there was "continuous day to day memory for at least 24 hours". ${ }^{4}$ He had subjects perform a small battery of tests that examined visual reproduction and associate learning. Subjects drew from memory three simple designs, each presented individually for 10 seconds as a test of visual memory. Associate learning was tested as follows: Subjects had three trials to learn 10 pairs of words; six obvious (up/down) and four difficult (cabbage/pen). The subjects were divided into three groups of severity as determined by persisting focal neurological signs. PTA duration, measured as described above, correlated with injury severity. However, there was no relation of these measures to commonly accepted current indices of severity such as the Glasgow Coma Scale. Moreover, we wished to validate a simpler bedside version of PTA assessment.

In 1979, the Galveston Orientation and Amnesia Test (GOAT) was described by Levin, O'Donnell and Grossman as an objective measure that may be administered repeatedly to chart recovery from PTA. ${ }^{5}$ The GOAT measures orientation to person, place and time as well as recall of historical events before and after the accident. A GOAT score of 70-75 has historically been considered the end of PTA. ${ }^{5}$ The GOAT, with documented reliability and construct validity, has become the standard instrument for the measurement of PTA. In 1988, the resolution of PTA was redefined as a GOAT score of 75 or higher on two consecutive days. ${ }^{6}$ The GOAT correlates significantly with scores on the Glasgow Coma Scale and with outcome from traumatic brain injury at six months. While a significant advance, the GOAT may depend to a large extent on overlearned new memories (orientation) and may not be sufficiently sensitive to the ability to learn and retain simple new information for at least 24 hours, a criterion that appears to be necessary if emergence from PTA means the return of continuous memory.

In 1980, Fortuny et al. described a simple quantitative test for measuring the duration of post-traumatic amnesia. ${ }^{7}$ By means of a simple questionnaire, the patient was asked about age, marital status, number of children, occupation as a test of orientation in time and space, and presented with a multiple choice regarding whether he was at home, in a hotel or a hospital. He was asked about memories of events prior to the accident and his first memories afterward. In addition to these orientation questions, the patient was shown three coloured pictures of common objects (a dog, a coat and an armchair) and was asked to name them. The patient was also asked to remember the examiner's face and first name. The following day, the examiner returned to give the same questionnaire and to check the recall of face, name and pictures. If spontaneous recall was imperfect, recognition of names and pictures was tested. This systematic approach was compared with an independent clinical estimate of duration of post-traumatic amnesia done by neurosurgical colleagues conducting a survey of the effects of head injury. The Fortuny questionnaire and the neurosurgical estimates matched well. No comparison was made to the GOAT.
Further refinement in the objective measurement of orientation and the day-to-day retention of new learned information has been proposed by Shores et al. who described the Westmead Clinical Scale for measuring the duration of post-traumatic amnesia. ${ }^{8}$ The Westmead PTA Scale tests continuous day-to-day memory by having the subject identify the face of the tester either in person or in picture and recognize three previously presented pictures in an array of nine pictures that includes the three targets and six distracters. Patients are considered to have emerged from PTA when they achieve a perfect score. The scale also includes tests of previously learned material such as the patient's age, date of birth; orientation (month, time of day, day of the week, year, name of the hospital) in addition to the continuous memory tests on three successive days. The end of PTA was defined as the first of the three successive days of perfect scores. Like the GOAT and the Fortuny questionnaire, there was a mix of potentially overlearned material (orientation) and new information to learn and retain. Again, there was no direct comparison to the GOAT, which has become a standard measurement of the termination of PTA.

The Galveston Orientation and Amnesia Test (GOAT), the Fortuny questionnaire and the Westmead PTA scale all combine tests of orientation and amnesia. They test for material that the patient knew prior to injury and do not control for variations in the frequency and vividness of presentation of information pertaining to orientation. While the Fortuny questionnaire and the Westmead PTA Scale do assess the ability to encode and recall information, there is no comparison of these to the GOAT.

\section{OBjective}

The current study was done to test the hypothesis that the ability to learn and retain new material will occur later than recovery of orientation as defined by a GOAT score of 75 or greater on two successive days. The hypothesis that the pattern of deficits in orientation and memory for the traumatic brain injury group (TBI) was not due to the general effects of hospitalization was tested by applying the same measures to matched controls admitted with multiple injuries but no brain injury and to orthopedic patients admitted for elective procedures.

The current study describes a bedside test of post-traumatic amnesia that may be administered in a moment and requires no equipment other than a pencil and paper.

\section{METHOD}

\section{Subjects}

The current study was conducted at two trauma units, Sunnybrook Health Science Centre and St. Michael's Hospital, in order to increase sample size and to assess whether the results would be comparable from one hospital to another. At Sunnybrook, we were able to detail some demographic features of the larger trauma population from which the brain-injured subjects in the study were drawn. During a 15 -month period, 670 patients were admitted to the Regional Trauma Unit at Sunnybrook. Of these, 469 were documented as having suffered a traumatic brain injury (TBI). Sixty of these patients expired in hospital, leaving 409 potential subjects. In addition, a limited number of patients (65) with TBI only and no multiple injuries, were admitted directly to the division of neurosurgery.

All these patients were assessed for eligibility for the current 
study according to the following criteria: Subjects were required to be between the ages of 16 and 65 , without previous head or spinal cord injury, without significant alcohol or drug abuse according to DSM-III- $\mathrm{R}^{9}$ criteria and without documented systemic or psychiatric illness. Patients were also excluded if they were illiterate, spoke limited or no English or if their jaws were wired shut. If a significant hypotensive or hypoxic episode was identified during resuscitation or if a patient was still unresponsive or not obeying commands after one month, the patient was not invited to participate. Informed consent was obtained from the family and, if possible, from the patient.

Of the total pool of patients, 164 were considered eligible for the study. Nine further patients were excluded because, on testing, they were found to be illiterate or insufficiently fluent in English, had a previous $\mathrm{CHI}$, or were alcohol dependent. Of the remaining 155, 20 could not be entered into the study because of the demands of concurrent care. The remaining 135 potential research subjects or their families were contacted to participate in the study. Ninety-four agreed and the rest refused.

In a 13-month period, 33 patients were contacted at St. Michael's Hospital. One failed to meet the inclusion criteria and nine refused. As noted in Table 1, there were no significant differences between the participant and refusal groups at their respective centres, in terms of gender, age (although refusals were somewhat older), severity of injury as determined by the Glasgow Coma Scale (GCS) ${ }^{10.11}$ at six hours, or the Injury Severity Score (ISS). ${ }^{12.13}$ Those who refused at Sunnybrook were hospitalized longer.

Table 1: Breakdown of Eligible Subjects.

\begin{tabular}{|c|c|c|c|c|}
\hline & \multicolumn{2}{|c|}{ SHSC } & \multicolumn{2}{|c|}{ SMH } \\
\hline & Participants & Refusals & $\overline{\text { Participants }}$ & Refusals \\
\hline Number & 94 & 41 & 23 & 9 \\
\hline Male & $57(0.61)$ & $23(0.56)$ & $12(0.52)$ & $6(0.67)$ \\
\hline Female & 37 & 18 & 11 & 3 \\
\hline \multicolumn{5}{|l|}{ Age (years) } \\
\hline Mean & 28.9 & 32.9 & 29.6 & 38.0 \\
\hline Std Dev & 10.8 & 12.4 & 12.3 & 9.2 \\
\hline Range & $16-63$ & $16-62$ & $16-62$ & $28-52$ \\
\hline \multicolumn{5}{|l|}{ Occupation } \\
\hline Unemployed & $3(0.03)$ & $5(0.12)$ & $5(0.22)$ & $3(0.43)$ \\
\hline Student & $26(0.28)$ & $6(0.15)$ & $7(0.30)$ & 0 \\
\hline Unskilled Labour & $23(0.25)$ & $13(0.32)$ & $2(0.09)$ & 0 \\
\hline Skilled Labour & $17(0.18)$ & $7(0.17)$ & $1(0.04)$ & 0 \\
\hline Professional & $24(0.26)$ & $10(0.24)$ & $8(0.35)$ & $4(0.57)$ \\
\hline \multicolumn{5}{|l|}{6 hour GCS } \\
\hline Mean & 12.1 & 12.7 & 12.7 & 10.7 \\
\hline Std Dev & 3.6 & 3.6 & 2.3 & 4.9 \\
\hline Range & $3-15$ & $3-15$ & $7-15$ & $3-15$ \\
\hline \multicolumn{5}{|c|}{ Duration of Hospitalization (days) } \\
\hline Mean & 19.4 & 25.6 & 17.5 & 17.1 \\
\hline Std Dev & 14.4 & 17.4 & 11.4 & 17.7 \\
\hline Range & $1-61$ & $5-80$ & $2-45$ & $3-52$ \\
\hline \multicolumn{5}{|l|}{ Injury Severity Score } \\
\hline Mean & 23.2 & 25.8 & 21.5 & 24.3 \\
\hline Std Dev & 11.2 & 10.5 & 7.5 & 16.2 \\
\hline Range & $5-54$ & $9-50$ & $6-30$ & $5-50$ \\
\hline
\end{tabular}

Gender and Occupation statistics are counts (with proportions in parentheses).
There were no significant differences between the participants in both centres. Together this provided us with a cohort of 117 TBI survivors. However, only 91 had enough test data for subsequent analyses.

The severity of injury was determined by the GCS at six hours post-injury. ${ }^{10,11}$ The GCS at six hours post-injury was used to subdivide the patients into the following three categories of severity: minor (GCS $=13$ to 15$)$, moderate $(\mathrm{GCS}=9$ to 12$)$ and severe (GCS $=3$ to 8 ). Table 2 summarizes the demographic characteristics of included patients by category of severity and the control subjects at both hospitals.

There were four control groups. All control subjects fulfilled the eligibility criteria noted above and were age and sex matched to the TBI group. Orthopedic control subjects were inpatients at Sunnybrook Health Science Centre admitted for diagnoses unrelated to the central nervous system or trauma. Spinal control subjects were surgical inpatients treated for spinal conditions unrelated to trauma. Spinal trauma control subjects were surgical inpatients treated for spinal cord injury who had no documented TBI. The normal control subjects were volunteers recruited by advertisement in the Sunnybrook Hospital newsletter and were chosen to be as equivalent to the TBI group as possible.

The data from a number of subjects who originally agreed to participate were not obtained or were incomplete to the extent that they could not be used for one or more of the following reasons: death, early discharge from hospital, medical reasons causing inability to respond, and/or scheduling difficulties caused by concurrent care. Analyses were completed only for the subjects who had sufficient data. The demographic characteristics of the 91 patients used in the analysis are shown in Table 3 and do not differ significantly from the patients who refused participation or had insufficient data in terms of age, gender, GCS, or length of hospitalization.

\section{Assessment}

a) All subjects underwent a general medical and neurological examination as part of their initial assessment and resuscitation that was recorded with the aid of a standardized trauma data entry form. ${ }^{14}$ All patients had a CT scan on admission that was used to guide treatment and on subsequent review was classified according to the method described by Marshall et al. for use in the Traumatic Coma Data Bank. ${ }^{15}$ The Glasgow Coma Score, vital signs and medications were recorded in the standard hospital chart which was reviewed retrospectively. b) All patients in the study were tested with the Galveston Orientation and Amnesia Test (GOAT) in order to guide patient management and to serve as a "gold standard" against which to compare the measures tested in the current study. c) All subjects were tested for the ability to learn and retain new information according to the following paradigms.

\section{Learning new information - words}

Sixty-six word triplets were created using a random numbers table to select the three words that formed each triplet. Care was taken to choose three words selected in matched triplets for equivalent scores of concreteness and frequency according to norms established by Paivio, Yuille and Madigan so as to remove from the study any bias created by sets that were easier or more difficult to recall. ${ }^{16}$ Thus, combinations could contain 
Table 2: Demographic Profile of Patients and Control Subjects.

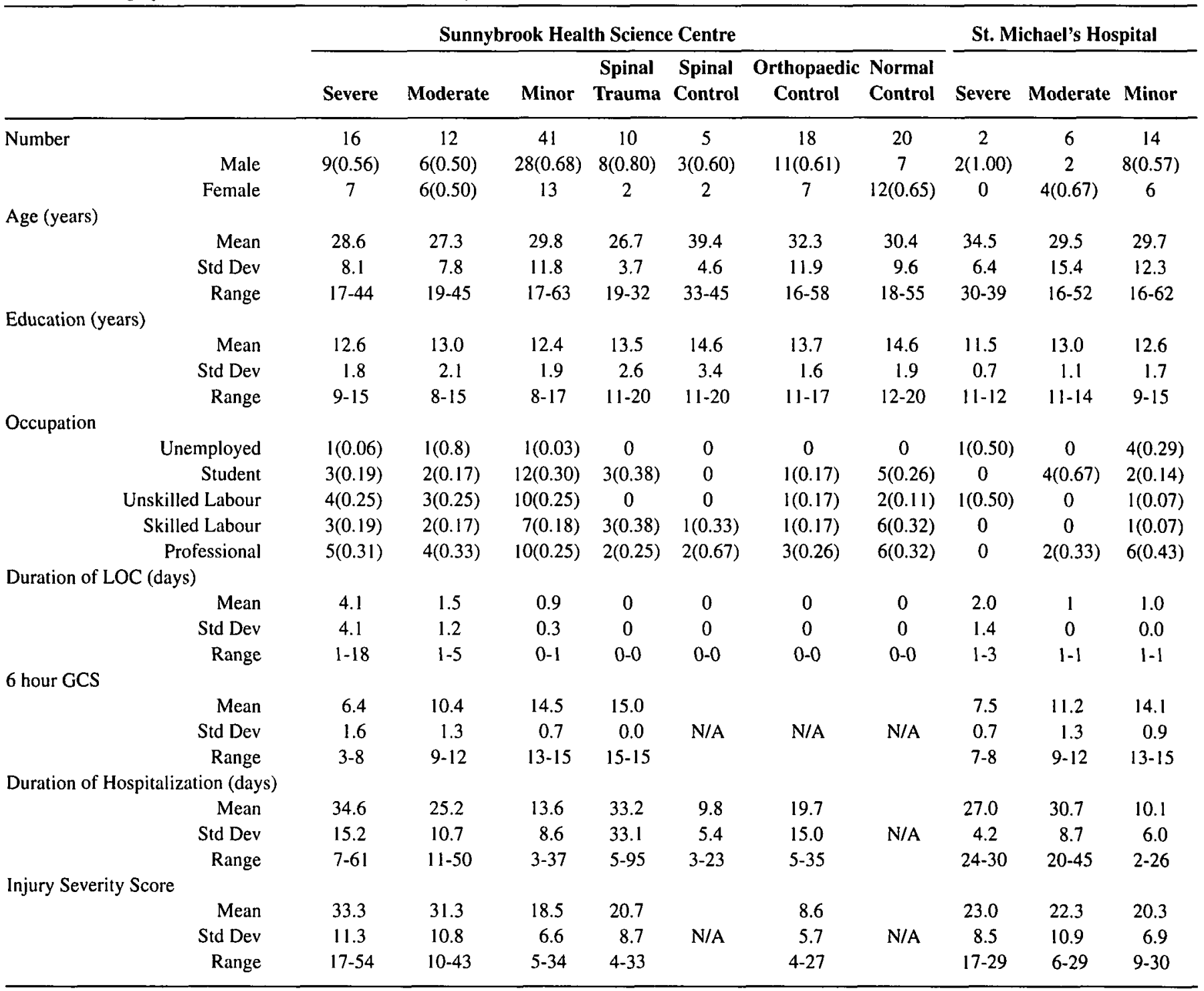

Gender and Occupation statistics are counts (with proportions in parentheses).

words of a high, medium or low value for each factor but the score for the triplet was required to fall in the medium range. Three examples are "injury, busybody, position", "mother, bravery, angle" and "restaurant, situation, limelight".

Once the 66 word triplets were formed, each set of three words was randomly assigned to one of three groups of words, thus yielding three equivalent groups of 22 triplets. Statistical analyses confirmed that mean concreteness and frequency values did not differ across these groups. Furthermore, word length did not differ across these groups.

The process for presenting the material to subjects was as follows:

1. Encoding: Subjects were instructed to look at each word individually for 10 seconds and to read the word aloud in order to enhance the probability that attention was being paid to each word and thus to maximize the patient's ability to learn the words.

2. Immediate recall: Subjects were asked to recall the three words immediately after the presentation of the last word.
Regardless of their performance in immediate recall, there was no correction and no further repetition. The patients were, however, reminded to remember the words for the next day.

3. Twenty-four hour recall: Subjects were asked to recall the three words of the previous days' encoding and immediate recall. If recall of the three words was perfect, the patients were considered to have met the criterion of the retention of new information over 24 hours. If recall was not perfect, the examiner administered the recognition task.

4. Recognition: Nine words, the three target words and six distracters, were presented individually and in random order. Subjects were asked to indicate which words they recognized from the day before. If there were any errors, the same three target words were then presented for encoding in the manner described above. That is, the subjects were given a second chance to encode the same three words and recall them after a 24-hour delay. 
Table 3: Breakdown of Analyzed Subjects.

\begin{tabular}{lccc}
\hline & Analyzed & $\begin{array}{c}\text { Refused or } \\
\text { Insufficient Data }\end{array}$ \\
\hline Number & Male & $55(0.60)$ & 76 \\
& Female & 36 & $43(0.57)$ \\
Age (years) & & & 33 \\
& Mean & 29.60 & 31.46 \\
& Std Dev & 10.8 & 12.3 \\
6 hour GCS & & & \\
& Mean & 11.95 & 12.63 \\
& Std Dev & 3.4 & 3.6 \\
Duration of Hospitalization (days) & & \\
& Mean & 20.12 & 21.12 \\
& Std Dev & 13.4 & 17.2 \\
Injury Severity Score & & \\
& Mean & 23.85 & 23.60 \\
& Std Dev & 10.7 & 10.8 \\
\hline
\end{tabular}

Gender statistics are counts (with proportions in parentheses).

Subjects were tested daily at approximately the same time each day, as their schedule permitted. Days were missed if the subject was unable to participate or refused testing for that day. Subjects were generally not tested on weekends. Subjects remained in the study until performance criterion was reached, they refused to continue or were released from hospital.

\section{Learning new information - pictures}

In addition to the presentation and testing of word triplets, subjects were also encoded, tested for immediate recall and for 24-hour recognition and recall with triplets of line drawings as described by Snodgrass and Vanderwart. ${ }^{17}$ The procedure was similar to that for the words. One purpose of including the pictures was to compare the sensitivity and practicality of the two modes of presentation. Because of the enhanced imagery with pictures, it was expected memory for pictures would recover first. Moreover, since certain patients may have focal memory deficits, the study would provide possible validation for two material specific approaches that could be used to test PTA independent of a focal memory impairment.

\section{Dependent Measurements}

A GOAT score of at least 75 for two consecutive assessments has been used as the criterion of resolution of PTA. ${ }^{6}$ In this study, this was arbitrarily defined as the point of comparison for the three-word test. There were two dependent measures from the three-word test. The number of words correctly recalled after a 24-hour delay was the measure of free recall. The measure of recognition, consisted of the number of words correctly recognized after a 24-hour delay minus the number of distracter words selected (hits minus false alarms). A score of $3 / 3$ was a perfect score for both the recall and recognition tasks.

The primary comparisons of interest were the relationship of perfect recognition and perfect recall to the first time the subject achieved a score of 75 or more on the GOAT for two successive days. For the sake of analyses described below, these were labeled as primary (GOAT) or secondary (three-word) events.
The number of days separating the secondary events from the primary event were analyzed, using the non-parametric sign test, where positive values indicated that the secondary event occurred after the primary event and negative values indicated that the secondary event preceded the primary.

\section{Censored Data}

Because of the difficulty in assessing subjects through the entire range of recovery, the concept of censored data was used in the analysis. ${ }^{18}$ When an event occurs outside the period of observation, then that event is said to be censored. More specifically, an event is said to be left or right censored when it occurs, respectively, prior to or subsequent to the period of observation. For example, if a patient presented on the first two days of testing with a GOAT score of greater than 75 on both days, then the event of achieving criterion on the GOAT is said to be left censored for this patient. When left censored data are used to estimate level of performance, the days to recovery of normal functioning may be overestimated. For example, if the first available data obtained on day 10 indicate normal performance, it is possible that this had been achieved earlier (e.g., day 7), but was not documented. In such a case, the estimate of a difference between recovery of the GOAT and a later recovery of another test (e.g., day 15) may be conservative (e.g., $15-10=5 \mathrm{v} .15-7=8$ ).

Calculating the number of days before or after achieving criterion on the GOAT that the patient first reached criterion for recognition and recall tasks was simple when no event was censored. If one or both of the primary and one of the secondary events was censored, then the minimum number of days separating the two events was assessed by substituting the first day of observation for the left censored event and substituting the day after the last day of observation for the right censored event. No estimate could be made when both events were either left censored or right censored. For example, if a subject consistently tested less than 75 on the GOAT and was never able to recognize or recall all three words before transfer or discharge from the acute care facility or death, then there would be no information regarding when the patient was able to recognize or recall all three words correctly relative to reaching criterion on the GOAT. Since not every subject had data for all measures for the above reasons, the sample size varied for certain analyses. The number of subjects $(\mathrm{n})$ in each analysis is indicated.

\section{RESULTS}

There were 14 orthopedic control subjects, 4 spinal control subjects, and 9 spinal trauma control subjects with a sufficient number of testing days to provide information about their 24hour recall and recognition in relation to the GOAT. The event of achieving a GOAT score in excess of 75 over two consecutive days was left censored for every one of these control subjects. In fact, their average GOAT score on the first day of testing was over 97 , indicating very early recovery of performance on this test, or perhaps no impairment at all. Achieving perfect scores on the four memory tasks was also highly left censored. Across the three hospitalized control groups $48 \%, 78 \%, 70 \%$ and $89 \%$ of the subjects were left censored on the word recall, word recognition, picture recall, and picture recognition tasks, respectively. The first day of testing for these hospitalized control subjects was early, on average 2.25 days post admission with a 
minimum of 0 and maximum of 9 days. In addition, $30 \%$ of these subjects were right censored on the word recall task and one of the subjects was also right censored on the other three 24-hour memory tasks. This suggests that the control subjects reached normal performance levels quickly, all but one were discharged with no evidence of deficit on three of the four memory tests, and that only word recall was impaired on discharge in 30 percent. For the few who were not censored on these tasks, the median number of days of 24-hour memory testing until achieving a perfect score on these tests ranged from one to two days.

There were 19 normal control subjects. They were not tested on the GOAT since many of the questions refer to an injury or hospitalization and therefore are not applicable to this group. Similarly to the hospitalized control groups, high percentages of the normal subjects were left censored on the memory tasks. The left censoring rates were $53 \%, 89 \%, 84 \%$, and $100 \%$ for the word recall and recognition and picture recall and recognition tasks, respectively. That is, close to $50 \%$ of the normal control subjects could not spontaneously recall the three words after the first 24 hour period. By the second day of testing $100 \%$ had achieved a perfect word recall score.

The nine patients who had suffered spinal cord injuries were an insufficient number to test the null hypothesis proposed by Davidoff et al. that patients who suffer spinal cord injuries without apparent TBI may also have post-traumatic amnesia, as documented by the Galveston Orientation and Amnesia Test. ${ }^{19}$ However, as a group they recovered on all measures of PTA faster than those with documented minor TBI, suggesting that it should not automatically be concluded that being in an accident sufficiently severe to cause spinal cord injury will also result in brain injury. The time to recovery of three-word recall was shorter for the spinal trauma patients than for the minor $\mathrm{CHI}$ patients $\left(X_{\text {Logrank }}^{2}=4.66, \mathrm{df}=1, \mathrm{p}=.03\right)$.
As there were no demographic differences in the TBI groups acquired at Sunnybrook and St. Michael's, the patients from both hospitals were combined. After exclusions, as listed above, 91 subjects with 53 minor, 19 moderate and 19 severe injuries, as defined by the Glasgow Coma Score at six hours after admission had sufficiently complete data sets to permit analysis. Figure 1 is a Kaplan-Meier plot indicating the proportion of control subjects and patients in each of the three severity categories in relation to the time to obtain perfect three-word free recall. ${ }^{18}$ The steeper the decline, the more rapid the recovery. The clear separation between the three tracings representing minor, moderate and severe injury indicates that the simple measure of presenting three words and testing for perfect free recall is a measure that corresponds to injury severity as determined by the GCS. Observe that some control subjects do not immediately achieve the free recall criterion.

The non-parametric sign test was used to test the hypothesis that perfect three-word free recall was achieved at the same time as the GOAT score exceeded 75 on two successive days. For all three patients groups (minor, moderate and severe) the sign test indicated, at a $95 \%$ level of confidence, that the median difference between the date that perfect three-word free recall was achieved and the date on which the GOAT score exceeded 75 on two successive days was not equal to zero. The median number of days after the GOAT score exceeded 75 on two consecutive days that the patient successfully recalled three words was two days for the minor group $(n=51, p<0.0001)$, three days for the moderate group $(n=15, p=0.01)$ and three days for the severe group $(n=14, p=0.002)$. That is, using a conservative measure, the GOAT underestimated the patient's ability to recall simple information over a 24 hour period. Figure 2 shows tracings of the GOAT scores of recovering patients in the minor, moderate and severe injury categories. The tracings of the GOAT scores

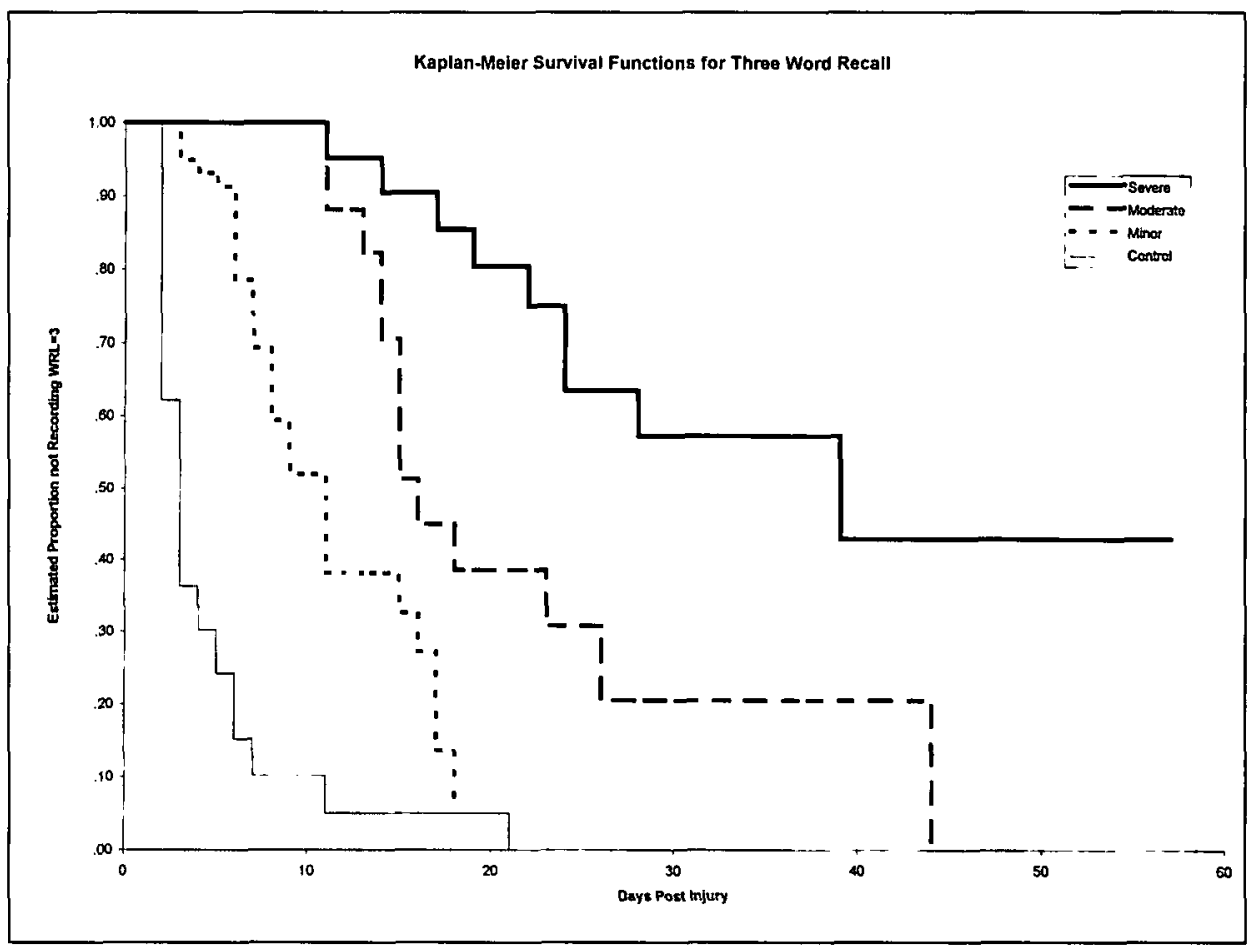

Figure 1: Kaplan-Meler Survival Functions for Three Word Recall 


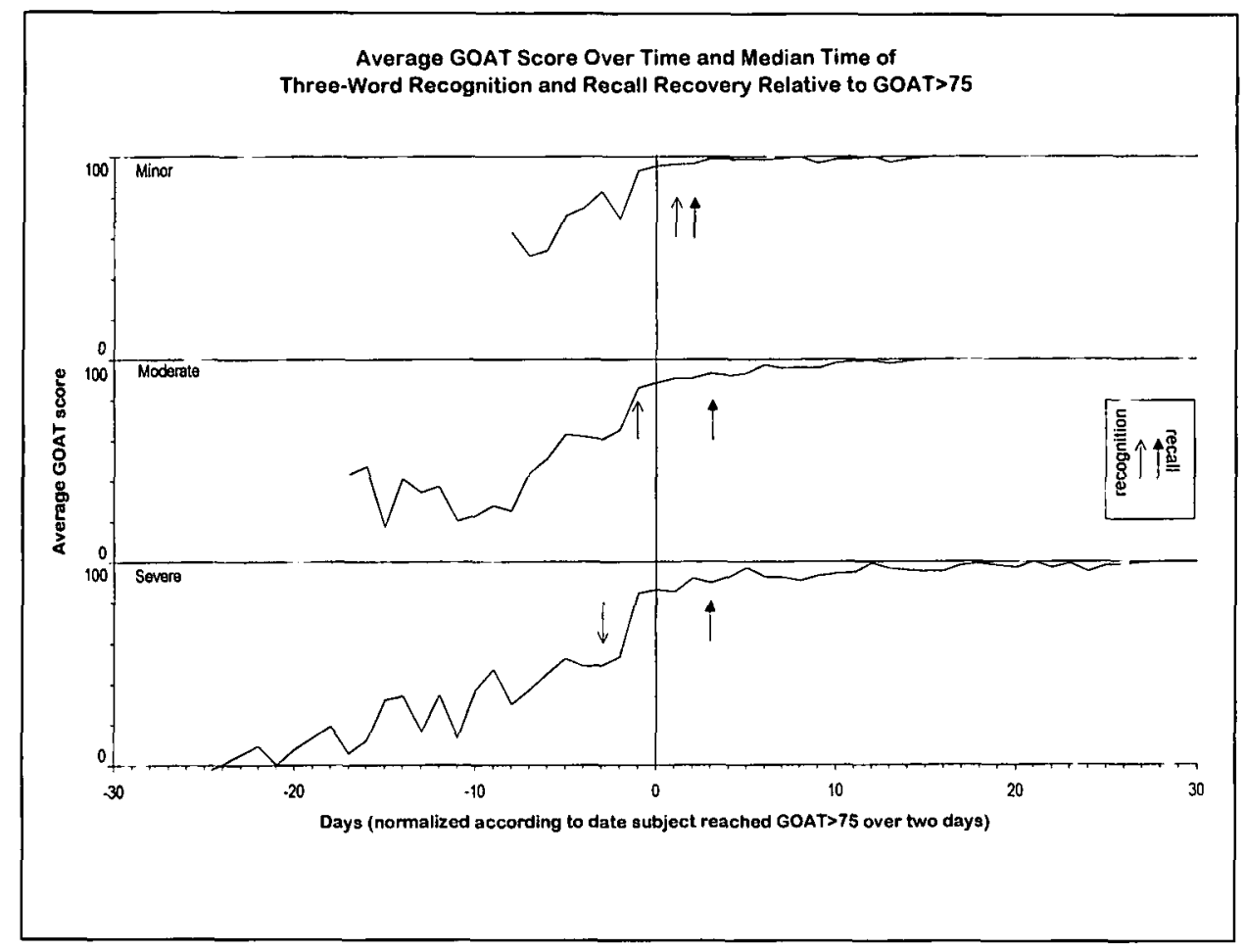

Figure 2: Average GOAT Score Over Time and Median Time of Three-Word Recognition and Recall Recovery Relative to GOAT $>75$.

rising over time are normalized by assigning the achievement of GOAT criterion (75 or greater on two successive days) to day zero. In this way, the rate of recovery for the three severity groups may be compared and secondary events such as perfect word recognition and recall may be related. When we include only those patients whose three-word recall event is not censored we are able to estimate the expected GOAT score at the time of the event based on a subset of the sample. This excludes subjects whose three-word recall either recovered quickly enough that their observations were left censored or was impaired enough that their observations were right censored. The GOAT scores at recovery of perfect three-word recall corresponding to minor, moderate and severe injuries, were $97 \mathrm{n}=$ 23), $90(n=12)$ and $88(n=9)$. That is, for a subject with any severity of TBI to recall three words over 24 hours, on average, a minimal GOAT score of 88 must be achieved.

The second dependent measure was the number of words correctly recognized after a 24-hour delay. For the moderate and severe injury categories, the median number of days before the GOAT score exceeded 75 on two consecutive days that the patient successfully recognized three words was one day ( $\mathrm{n}=$ $12, p=0.34)$ and 3 days $(n=17, p=0.12)$. The median number of days after the GOAT score reached criterion, that perfect recognition was achieved for the minor TBI group was one day $(\mathrm{n}=30, \mathrm{p}<0.0001)$. The average GOAT scores for non-censored patients at recovery of perfect three-word recognition for minor, moderate and severe brain injuries were $97(n=18), 76$ $(n=11)$ and $68(n=13)$, respectively. Using the sign test it was determined that word recognition preceded word recall by 1.5 days $(n=42, p<.0001)$ for the minor brain injury group, by three days $(\mathrm{n}=15, \mathrm{p}=.0001)$ for the moderate group, and by three days $(n=17, p=.0001)$ for the severe group. While cor- rect word recognition occurred later than the time of the GOAT reaching a normal criterion level, recognition and the GOAT were more comparable in time of recovery than free recall.

Picture recognition preceded picture recall by a median of one day $(\mathrm{n}=29, \mathrm{p}<.0001)$, two days $(\mathrm{n}=15, \mathrm{p}=.0005)$, and three days $(n=18, p=.0001)$ for the minor, moderate and severe head injury groups respectively. Picture recall preceded word recall by one day $(n=43, p<.0001)$ for the minor group, by one day $(n=14, p=.02)$ for the moderate group, and by three days $(n=12, p=.01)$ for the severe group. Picture recognition preceded word recognition for minor $(n=30, p=.006)$ and severe $(n=16, p=.007)$ groups both by one day. For the moderate group there was no significant difference between picture recognition and word recognition $(n=13, p=.34)$.

Memory of pictures recovered more quickly than memory of words. Perfect three-picture recognition for moderate and severe brain injury categories preceded GOAT criterion by a median of one and four days respectively. Perfect three-picture recognition followed GOAT criterion by one day for minor injuries. Perfect recall of pictures occurred one day after achievement of GOAT criterion for minor and moderately injured patients, and the median difference between perfect recall of pictures and achievement of GOAT criterion was 0 days for the severely injured patients.

Figure 3 plots the relative frequency of particular durations of post-traumatic amnesia for the three severities of injury. If a patient's date of recovery was right censored then an estimated date of recovery was calculated based on the average time to recovery for those patients in the same severity group for whom we have an observed date of recovery of function, defined by word-recall, before discharge. This was possible except for the most severely injured patients. For these patients, there may be 


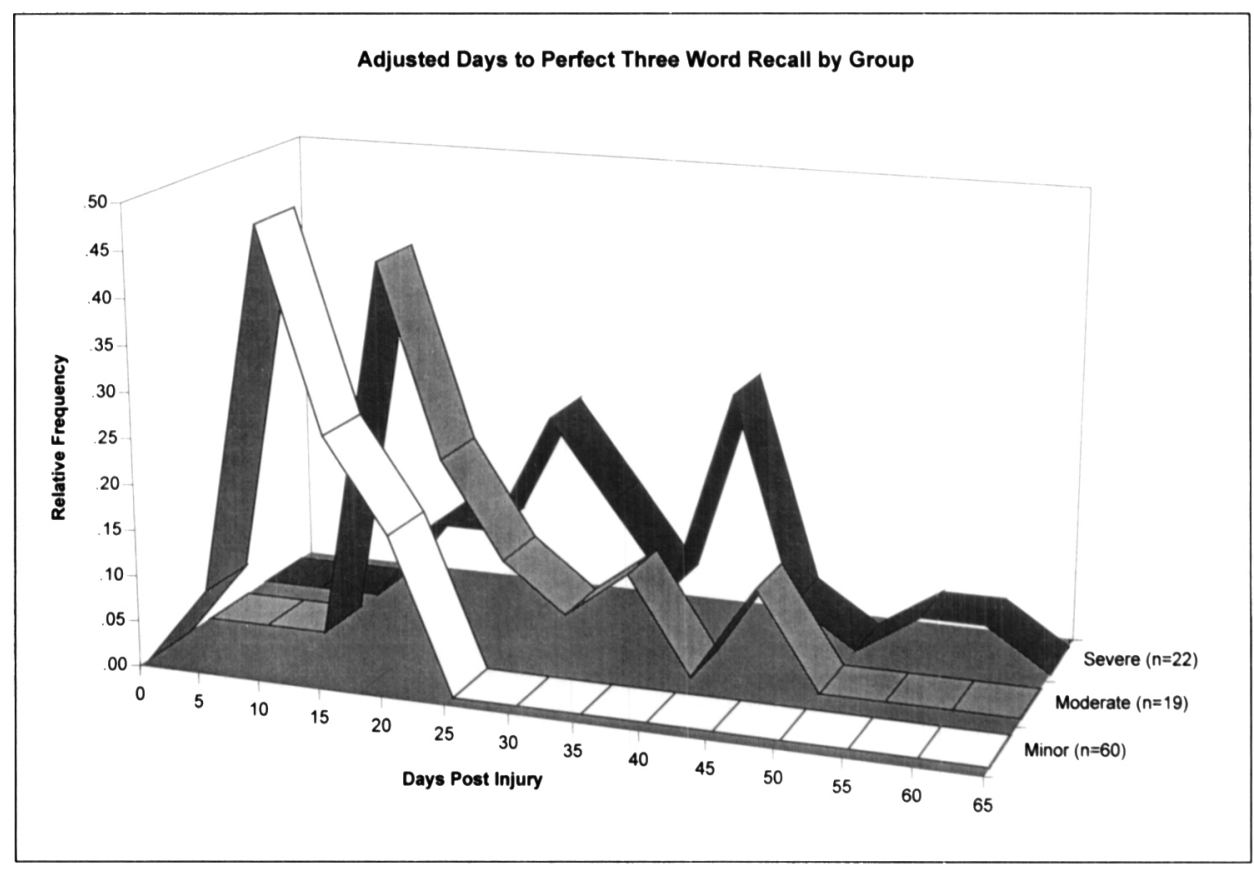

Figure 3: Adjusted Days to Perfect Three Word Recall by Group.

three clusters of rates of recovery. Cluster 1 recovers more quickly with PTA as tested by three-word recall extending up to about 30 days $(n=13)$. In cluster 2, PTA persists for about 30 to 45 days $(n=7)$ and in cluster 3 post-traumatic amnesia persists for more than 45 days $(n=2)$. As expected, the length of hospitalization was significantly longer for clusters 2 and 3 (averages of 43 and 56 days respectively) than for cluster 1 (average of 27.5 days $)\left(F_{2,19}=7.29, p=.005\right)$. There were nominal associations of age (averages of $26.5,32.0$, and 35.5 years), injury severity score (averages of $30.8,34.4$, and 40.5 ), length of loss of consciousness (averages of 76.8, 124.6, and 252.0 hours) and six-hour GCS (averages of 6.8, 6.1, and 4.5) with these clusters ( 1,2 , and 3 respectively). However, these differences were not statistically significant. There was no difference among clusters in education level.

On chart review, an attempt was made to identify whether the use of drugs known to affect the central nervous system interfered with apparent recovery from post-traumatic amnesia. As it is the current practice to prescribe haloperidol, chlorpromazine and propranolol for agitated patients and since agitation is presumably in large measure an effect of impaired cognition and memory, the drug effect was impossible to isolate reliably. Furthermore, certain drugs such as propranolol prescribed for agitation, cisapride and metoclopramide prescribed to enhance gastric motility, while not characteristically expected to produce confusion or even somnolence, may occasionally do so. This further clouds the issue of drug effect.

\section{Discussion}

The clear separation between the three tracings in Figure 1 representing minor, moderate and severe injuries indicates that the simple measure of presenting three words and testing for perfect free recall has construct validity as minor, moderate and severe injuries characteristically recover at faster, intermediate and slower rates respectively. This is taken as direct evidence that the length of PTA as measured by "three little words" is indeed an indicator of severity of injury.

This study establishes a relationship between the re-establishment of continuous day-to-day memory for at least 24 hours and the standard measure of post-traumatic amnesia, the Galveston Orientation and Amnesia Test. In the moderate and severe TBI groups recognition and recall tend to bracket the GOAT criterion of recovery with recognition preceding and recall following. It is possible that three-word recognition which follows the GOAT criterion in minor head injuries is an artifact of left censoring as word recognition may indeed have preceded the achievement of the GOAT criterion of recovery but testing began too late to detect it.

This relationship of recognition recovery at approximately the same time on or before the GOAT, and recall following the GOAT, makes sense practically and cognitively. The GOAT combines tests of orientation and amnesia. This combination may be useful in patient management but the combination obscures the study of the recovery from post-traumatic amnesia. The GOAT contains material that the patient knew prior to injury, and might be able to be retrieved with less effort. Recognition memory similarly requires less cognitive effort from the patient. Moreover, the GOAT does not control for variations in the frequency and vividness of presentation of information intended to help the patient recover orientation. For example, some patients may be told the date and place hourly, whereas others may live a succession of monotonous hospital days without this information being presented. It is probable that orientation measures obscure measures of amnesia and, in our view, should be tested separately. Free recall of information presented 24 hours earlier is a more demanding task, requiring greater retrieval effort. In fact, only about $50 \%$ of the control subjects of any type were able to recall the three words on the first day of testing. (100\% recalled them on the second day.) The fact that 
recognition precedes recall also indicates that the information has been encoded but cannot be spontaneously used. This may reflect our clinical observations that patients seem to have acquired certain information, but do not use it spontaneously.

Since recognition and recall of pictures bear a constant temporal relationship to recognition and recall of words, it may be that for patients who are dysphasic or who do not share a common language with the examiner, three-picture recognition and recall are a reliable substitute for word recognition and recall.

As the efficacy of a rehabilitation program or the safety of the patient in a relatively unsupervised home environment depend on the ability to learn and recall new information, the criterion of achievement of a GOAT score of 75 on two successive days may precipitate a premature transfer from the acute care setting. As the GOAT score was on average 90 and 88 for moderately and severely injured patients respectively before they were able to recall information as simple as three mediumfrequency concrete words without prompting for 24 hours at a time, one may conclude that the three-word recall test is a simpler and preferable alternative to the GOAT as an indicator of recovery from PTA, if PTA is defined as the recovery of continuous memory. Certainly, the measures provide different information about the recovery of cognitive processes after TBI. It may also be that three word recall as a measure of PTA may be a more sensitive predictive measure of eventual recovery.

\section{Conclusion}

It is recommended to clinicians who care for patients who have suffered head injuries that on making rounds, they encode and test immediate recall, using three words that they (the clinicians) can remember. On making rounds the following day, recall of the three words may be tested and re-encoding done as required. While the three word test may be too sensitive for a single 24 hour assessment (note the performance of the control subjects), if used together with another measure of encoding such as orientation (GOAT) or recognition, it can provide a reasonable estimate of the cognitive status of the patient. A reliable assessment of emergence from PTA may then be made and a safe decision regarding patient disposition arrived at. Equipment required: pencil and paper.

\section{ACKNOWLEDGEMENTS}

This study was funded by the Ontario Mental Health Foundation. Partial data were initially presented at the 2nd International Neurotrauma Symposium, Glasgow, 1993 and the 3rd International Neurotrauma Symposium, Toronto, 1995. Additional testing and organizational assistance were provided by L. Sayer, L. Buckle, M. Wasdell, E. Kerbel, J. Shulman, R. Schwartz and I. Sullivan. We are grateful to the patients and families who consented and gave of their time, and to the nurses and physicians of the patients of both hospitals, who co-operated in the successful completion of the study.

\section{REFERENCES}

1. Miller H. Mental after-effects of head injury. Proc Roy Soc Med 1966; 59: 257-261.

2. Symonds CP, Russell WR. Accidental head injuries. Lancet 1943; 2: 7-10.

3. Gronwall D, Wrightson P. Duration of post-traumatic amnesia after mild head injury. J Clin Neuropsychol 1980; 2: 51-60.

4. Brooks DN. Wechsler Memory Scale performance and its relationship to brain damage after severe closed head injury. J Neurol Neurosurg Psychiatry 1976; 39: 593-601.

5. Levin HS, O'Donnell VM, Grossman RG. Galveston Orientation and Amnesia Test. A practical scale to assess cognition after head injury. J Nerv Ment Dis 1979; 167: 675-684.

6. Levin HS, High WM, Eisenberg HM. Learning and forgetting during post-traumatic amnesia in head injured patients. J Neurol Neurosurg Psychiatry 1988; 51: 14-20.

7. Fortuny LAI, Briggs M, Newcombe F, Ratcliff G, Thomas C. Measuring the duration of post traumatic amnesia. J Neurol Neurosurg Psychiatry 1980; 43(5): 377-379.

8. Shores EA, Marossezeky JE, Sandanam J, Batchelor J. Preliminary validation of a clinical scale for measuring the duration of posttraumatic amnesia. Med J Aust 1986; 144: 569-572.

9. American Psychological Association. Diagnostic and Statistical Manual of Mental Disorders. (Revised 3rd Edition). Washington, DC: American Psychological Association, 1987.

10. Teasdale G, Jennett B. Assessment of coma and impaired consciousness: a practical scale. Lancet 1974; 2: 81-84.

11. Jennett J, Snoek J, Bond MR, Brooks N. Disability after severe head injury: observations on the use of the Glasgow Outcome Scale. J Neurol Neurosurg Psychiatry 1981; 44; 285-293.

12. Baker SP. The Injury Severity Score: an update. J Trauma 1976; 16 : 822-885.

13. Baker SP, O'Neill B, Haddon W, Long WB. The Injury Severity Score: a method for describing patients with multiple injuries and evaluating emergency care. J Trauma 1974; 14: 187-196.

14. Kondziolka D, Schwartz ML, Walters BC, McNeill I. The Sunnybrook Neurotrauma Assessment Record: improving trauma data collection. J Trauma 1989; 29(6): 730-735.

15. Marshall LF, Marshall SB, Klauber MR, et al. A new classification of head injury based on computerized tomography. J Neurosurg 1991; 75: S14-S20.

16. Paivio A, Yuille JC, Madigan SA. Concreteness, imagery, and meaningfulness values for 925 nouns. J Exp Psych, Monograph Supplement 1968; 76(1, part 2).

17. Snodgrass JG, Vanderwart M. A standardized set of 260 pictures: norms for name agreement, image agreement, familiarity, and visual complexity. J Exp Psychol: Human Learning and Memory 1980; 6: 174-215.

18. Lawless JF. Statistical Models and Methods for Lifetime Data. New York: Wiley \& Sons, 1982.

19. Davidoff G, Doljanac R, Berent $S$, et al. Galveston Orientation and Amnesia Test: its utility in the determination of closed head injury in acute spinal cord injury patients. Arch Phys Med Rehabil 1989; 69 : 432-434. 